\title{
Aerodynamic Behavior of Snowflakes on an Uneven Road Surface during a Snowstorm
}

\author{
Kojima Tetsuya1, Yoichi Yamagishi' ${ }^{2}$, Shigeo Kimura², Kengo Sato ${ }^{3}$ \\ ${ }^{1}$ Meteorological Research Institute for Technology Co., LTD., Tokyo, Japan \\ ${ }^{2}$ Department of Mechanical Engineering, Kanagawa Institute of Technology, Kanagawa, Japan \\ ${ }^{3}$ National Research Institute for Earth Science and Disaster Resilience, Yamagata, Japan \\ Email: skimura@me.kanagawa-it.ac.jp
}

How to cite this paper: Tetsuya, K., Yamagishi, Y., Kimura, S. and Sato, K. (2017) Aerodynamic Behavior of Snowflakes on an Uneven Road Surface during a Snowstorm. Open Journal of Fluid Dynamics, 7, 696-708. https://doi.org/10.4236/ojfd.2017.74045

Received: November 26, 2017

Accepted: December 26, 2017

Published: December 29, 2017

Copyright (C) 2017 by authors and Scientific Research Publishing Inc. This work is licensed under the Creative Commons Attribution International License (CC BY 4.0).

http://creativecommons.org/licenses/by/4.0/

\section{cc) (i) Open Access}

\begin{abstract}
The removal of snow from a road or railroad results in an uneven surface and thus the formation of snowdrifts. However, the effect of a surface bump on the scale of a snowdrift is not clear. Snowdrift wind tunnel tests have long been performed to predict the snow cover distribution due to a snowstorm. However, such tests require a large-scale experimental device, have high installation and maintenance costs, and are not easy to perform. The present study thus used a small water tunnel that is easier to implement. The snowdrift pattern for the real phenomenon of a cube model was reproduced using the small water tunnel and the performance of the tunnel thus verified. The snowdrift water tunnel was then used to predict the snowdrift distribution for uneven surfaces. The tunnel well reproduced the snow cover distribution when the sedimentation velocity ratio and Stokes number in the water tunnel test were the same as those for the real phenomenon, again verifying the performance of the water tunnel test.
\end{abstract}

\section{Keywords}

Snowstorm Water Tank, Model Snow, Bump Model, Snowdrift Distribution, Numerical Analysis

\section{Introduction}

Japan is a country that experiences frequent snowfall which may cause various types of disasters or accidents in direct and indirect manners.

During a snowstorm, snowflakes are drifted leeward and accumulate in any place where the wind flow is weakened, which results in a formation of snow-mound defined as snowdrift.

Snowdrifts can be obviously one of the major causes of road accidents and the 
derailment of trains. It is thus important to predict the formation of snowdrifts due to snowstorms in order to take prevention measures. The removal of snow from a road or railroad will typically produce an uneven surface, and a snowdrift can pile high around such bumps. The scale of snowdrift has been clearly shown to depend on the snowfall, air temperature, and wind speed based on the previously conducted researches. However, the effect of a surface bump on the scale of snowdrift is not still clear. Snowdrift wind-tunnel tests have long been conducted for the prediction of the snow cover distribution due to a snowstorm. However, such testing requires a large-scale experimental device that has high installation and maintenance costs and is difficult to use. The present study thus used a small water tunnel that has been designed and built by the authors. The snowdrift pattern for the real phenomenon of a cube model was reproduced in the water tunnel test section, and the feasibility of predicting a snowdrift pattern was investigated by comparison with the field test results. Furthermore, the numerical analysis was performed so as to seek its applicability to the snowdrift formation as the complex two-phase flow problem.

\section{Experimental and Numerical Approaches}

\subsection{Snowdrift Water Tunnel}

We employed a snowstorm water tunnel having dimensions of $1020 \mathrm{~mm} 520$ $\mathrm{mm} 120 \mathrm{~mm}$ (and passage cross sections of $120 \mathrm{~mm} 80 \mathrm{~mm}$ ) at the Kanagawa Institute of Technology as shown in Figure 1. The blockage ratio of the test piece to the channel cross section was $5 \%$ or less and thus no blockage effect was expected. We used a current plate and honeycomb plate to produce a uniform flow. A current plate was installed in the angled part of the channel and a honeycomb plate was installed on the upper stream side of the test channel. A honeycomb structure is adopted in the straightening grating.

The horizontal and perpendicular components of the velocity distribution near the test piece are shown in Figure 2. The flow velocity $\mathrm{u}$ was normalized by the average flow velocity $U$, the position 1 perpendicular to the direction of flow was normalized by the depth $L$, and the height $h$ was normalized by channel
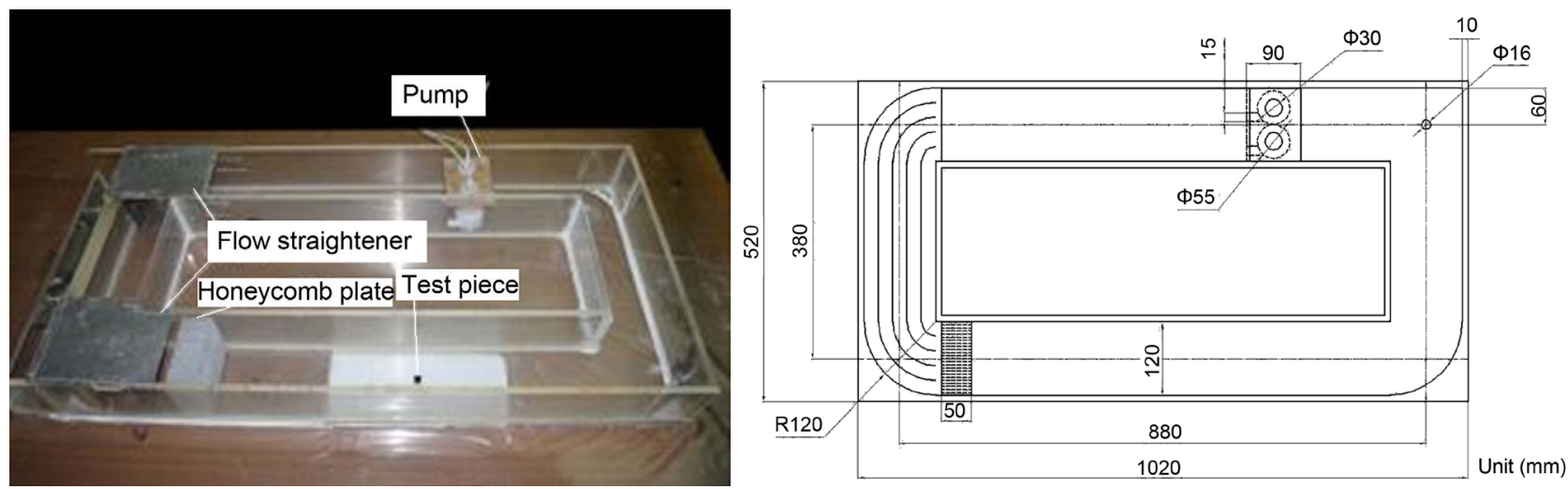

Figure 1. Water tunnel. 


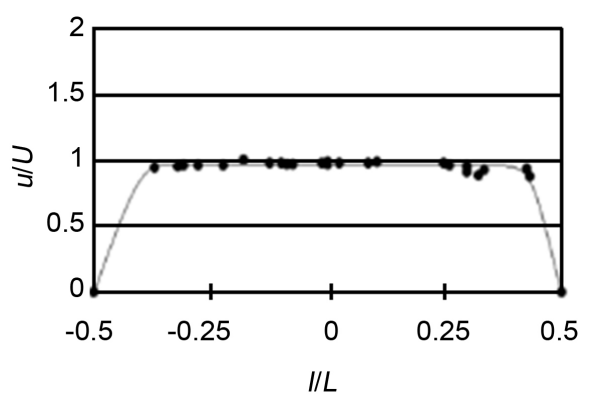

(a)

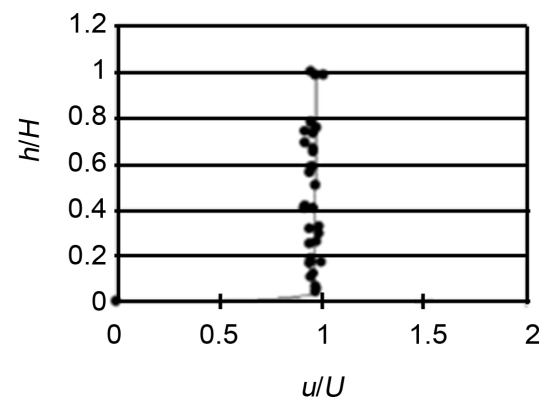

(b)

Figure 2. Velocity distributions of the passage cross section. (a) Horizontal velocity distribution; (b) Vertical velocity distribution.

height $\mathrm{H}$. The velocity distributions in channel cross sections indicated uniform flow.

Experiments were conducted by setting cubic and bump models on the bottom of the channel. Four small pumps were driven by an alternating-current potential transformer and established a flow velocity of water of 0.18 to 0.27 $\mathrm{m} \cdot \mathrm{s}^{-1}$. Model snow used in the experiments comprised alumina particles with diameter of $0.125-0.5 \mathrm{~mm}$, true density of $3580-3980 \mathrm{~kg} \cdot \mathrm{m}^{-3}$, sedimentation velocity of $0.0324-0.087 \mathrm{~m} \cdot \mathrm{s}^{-1}$ and friction velocity of $0.12-0.29 \mathrm{~m} \cdot \mathrm{s}^{-1}$.

The snowfall time $T$ is defined using the characteristic reference length $L$, the snow-drift transport rate $Q$, the capturing ratio of snow particle $\eta$, and the density $\rho$ as follows Anno's (1989) [1] Equation (1).

$$
\frac{T_{p}}{T_{m}}=\left(\frac{L_{p}}{L_{m}}\right)^{2} \frac{\left(Q_{m} \eta_{m} \rho_{p}\right)}{\left(Q_{p} \eta_{p} \rho_{m}\right)}
$$

where, $m$ : model; $p$ : prototype.

At the end of each experiment, the water in the tank was drained. After that the thickness of the alumina at the bottom of the tank and around the test piece was measured with a laser displacement meter.

\subsection{Test Piece}

The first series of snowstorm water-tunnel experiments were conducted using cubic models for comparison with a real phenomenon. Uneven (bump) models were then used in the second series of experiments.

\subsubsection{Cubic Model}

Two cubic models were used, one with lengths of $10-20 \mathrm{~mm}$. The cubic model with lengths of $10 \mathrm{~mm}$ is shown in Figure 3. Each cube was made of acrylic re$\sin$.

\subsubsection{Bump Model}

Figure 4(a) is a photograph of snow-removal work on a road. As a result of snow removal and as shown in Figure 4(b), the road surface has a cut-out shape, hereafter referred to as a cut-earth shape. 


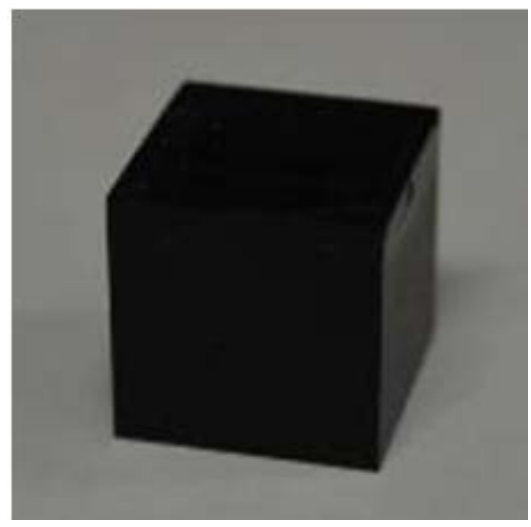

Figure 3. Cubic model.

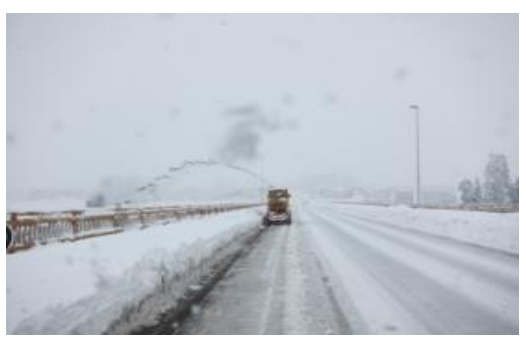

(a)

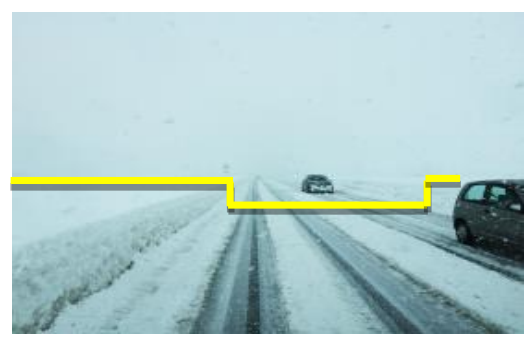

(b)

Figure 4. Photographs of snow-removal work. (a) During snow-removal work; (b) After snow-removal work.

The two bump models used in the experiment, namely a concave cut-earth model and a convex embankment model, are shown in Figure 5. The supposed road has a height of $2 \mathrm{~m}$, width of $32 \mathrm{~m}$ and a gradient of 1:1.5. Each model road has a height of $3 \mathrm{~mm}$, width of $50 \mathrm{~mm}$ and a gradient of 1:1.5, and thus a scale of $1 / 666$. The snowdrift distribution was investigated for the two models.

\subsubsection{Surface of the Test Piece}

The thickness of alumina particles covering the model attached and measured the laser displacement gauge sensor head (KEYENCE IL-300) to the actuator (IAI-RCP2-SA5C). The actuator was moved in intervals of $0.5 \mathrm{~mm}$, and the laser displacement gauge measured the deposition thickness of the imitation snow along the channel center in the direction of flow, and the measurement voltage was downloaded to a personal computer through a data logger (KEYENCE NR-110).

Because the sensor head is of diffusion laser receiver type, as shown by the red line in Figure 5 to the test piece of a smooth surface, it introduces measurement error. The exact result shown by the blue line in Figure 6 was then obtained by painting the surface of the test piece with paint having a roughness index of $\# 1000$ (Mr. white surface 1000).

\subsection{Experimental Conditions}

The cubic model was used to reproduce the snowstorm pattern of a real pheno- 
menon in a tank experiment, and the similarity was examined. Oikawa et al.
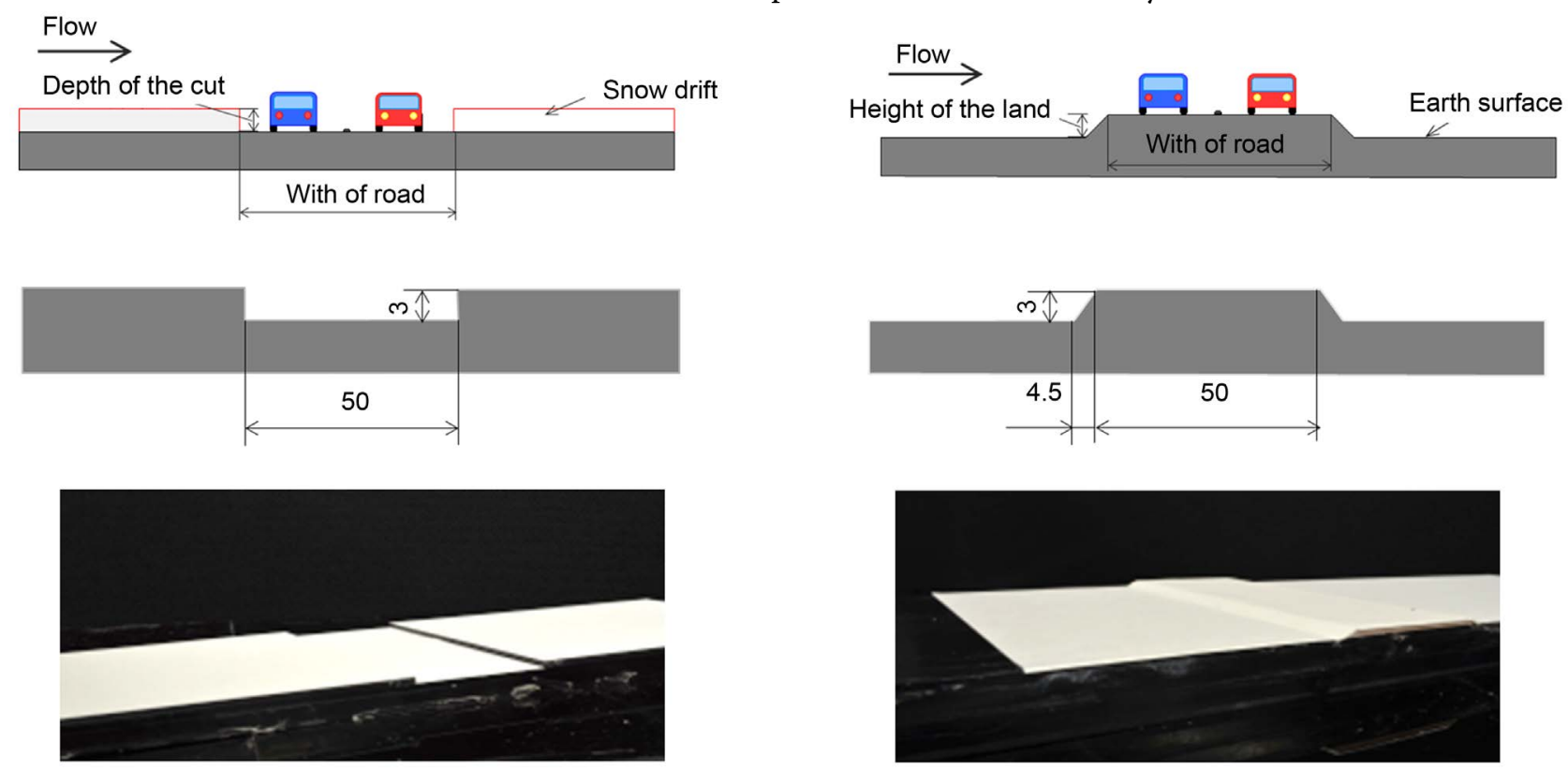

(a)

(b)

Figure 5. Bump models (unit: mm). (a) Cut-earth model; (b) Embankment model.

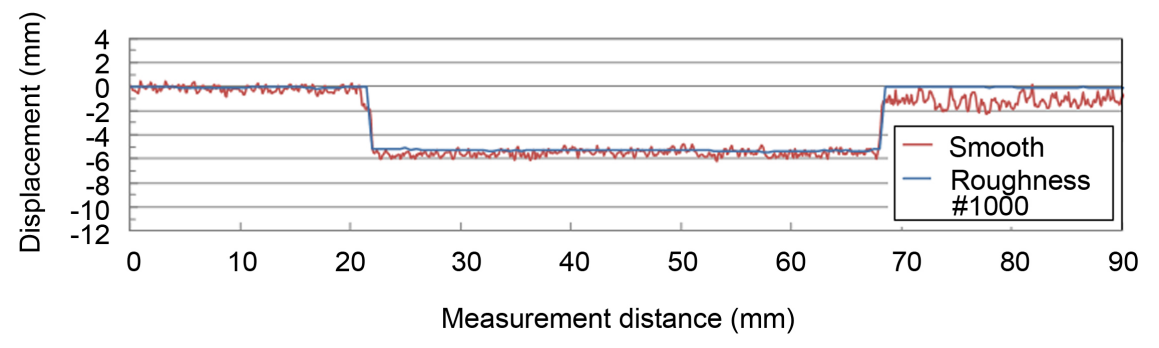

Figure 6. Measurement by a laser displacement gauge.

(2007) [2] thoroughly investigated the similarity of a real phenomenon and a snowstorm wind tunnel test for different geometric forms, such as geographical features and buildings. Conditions that need to be similar in the real phenomenon and the wind tunnel test are the angle of repose, the Froude number, the Stokes parameter, the snowdrift form and the sedimentation velocity ratio, which is the critical ratio at which particles are moved by the wind. According to Iversen (1979) [3] and Kind (1976) [4], the transportation of snow particles in a snowstorm is based on jumping movements. However, near a structure, there is complicated turbulent flow, the speed in the perpendicular direction becomes high compared with that for flat ground, and the floating movement of snow particles becomes dominant. Therefore, in a wind tunnel test for the situation near a building, the action of snow particles is based on floating movement.

Considering the above discussion, the requirement of similarity of the Froude number for the jumping movement is eased. Attention is instead paid to the Stokes number, which is an index of the tracking performance of particles and is 
related to the floating movement in a flow. Experiments were thus conducted using different diameters of the model snow particles, flow velocities, and lengths of the cube, for four Stokes numbers. The experimental conditions of snowstorm tank experiments $1-4$ are given in Table 1 . The real phenomenon conditions listed in Table 1 are based on the work of Oikawa et al. (2007).

Furthermore, in order to check the validity of the tank experiment, we performed numerical-analysis calculation currently used for snow cover prediction.

\subsection{Numerical Analysis}

The unsteady three-dimensional turbulent flow and the resulting snowdrift were analyzed for the bump model using the versatile fluid analysis software package Fluent 15 . The k- $\varepsilon$ model of the renormalization group (RNG) was used for multi-phase flow analysis of air and snow particles. The RNG model was developed using RNG methods to renormalize the Navier-Stokes equations and thus account for the effects of smaller scales of motion.

The Euler granular model was employed for the multi-phase flow model to solve the transport equation of the volume fraction (the volume ratio of snow particles to air). We supposed that the depth of snowfall can be expressed by the volume fraction of snow particles. Consequently, the saturation of space density is approached as the volume fraction of snow particles increases, and finally,

Table 1. Conditions of the snowstorm tank in the first series of experiments.

\begin{tabular}{|c|c|c|c|c|c|}
\hline & $\begin{array}{c}\text { Actual } \\
\text { phenomenon }\end{array}$ & $\begin{array}{c}\text { Experiment } \\
\text { number } 1\end{array}$ & $\begin{array}{l}\text { Experiment } \\
\text { number } 2\end{array}$ & $\begin{array}{c}\text { Experiment } \\
\text { Number } 3\end{array}$ & $\begin{array}{c}\text { Experiment } \\
\text { number } 4\end{array}$ \\
\hline $\begin{array}{c}\text { Particle } \\
\text { diameter }(\mathrm{mm})\end{array}$ & 0.2 & 0.125 & 0.165 & 0.3 & 0.5 \\
\hline $\begin{array}{c}\text { Particle } \\
\text { density }\left(\mathrm{kg} / \mathrm{m}^{3}\right)\end{array}$ & 980 & 3580 & 3980 & 3980 & 3980 \\
\hline $\begin{array}{c}\text { Fluid } \\
\text { density }\left(\mathrm{kg} / \mathrm{m}^{3}\right)\end{array}$ & 1.342 & 995.3 & 995.3 & 998.2 & 998.2 \\
\hline $\begin{array}{l}\text { Sedimentation } \\
\text { velocity }(\mathrm{m} / \mathrm{s})\end{array}$ & 1 & 0.0324 & 0.0348 & 0.0530 & 0.0870 \\
\hline $\begin{array}{c}\text { Fluid } \\
\text { velocity }(\mathrm{m} / \mathrm{s})\end{array}$ & 5 & 0.18 & 0.18 & 0.27 & 0.24 \\
\hline $\begin{array}{c}\text { Friction } \\
\text { velocity }(\mathrm{m} / \mathrm{s})\end{array}$ & 0.185 & 0.120 & 0.214 & 0.291 & 0.250 \\
\hline $\begin{array}{l}\text { Length of a side } \\
\qquad(\mathrm{mm})\end{array}$ & 1000 & 20 & 10 & 10 & 10 \\
\hline $\begin{array}{l}\text { Viscosity } \\
\left(10^{-3} \text { pa } \cdot s\right)\end{array}$ & 0.0167 & 0.874 & 0.874 & 0.936 & 0.936 \\
\hline $\begin{array}{l}\text { Stokes } \\
\text { number }\end{array}$ & 0.652 & 0.032 & 0.124 & 0.574 & 1.417 \\
\hline $\begin{array}{c}\text { Sedimentation } \\
\text { velocity ratio }\end{array}$ & 0.2 & 0.18 & 0.19 & 0.20 & 0.36 \\
\hline $\begin{array}{c}\text { Critical friction } \\
\text { velocity ratio }\end{array}$ & 0.037 & 0.667 & 1.18 & 1.07 & 1.04 \\
\hline
\end{tabular}


snow particles accumulate. It is therefore assumed that there is correlation between the snow volume fraction and snow depth. Thus, the portion in which particles stagnate was calculated as that having a large volume fraction.

The depth of snow cover was expressed as a volume fraction; i.e., the volume ratio of snow particles to air. The analysis conditions for a dump model were set the same as the conditions of the supposed road. Because the wind direction of the snowstorm was dominant in one direction, this wind direction was set as the orientation of the $\mathrm{x}$-axis in the numerical analysis. Figure 7 shows the analysis region for each dump model.

\section{Experimental Results}

\subsection{Performance of the Snowstorm Water Tunnel}

The results of a field test are in Figure 8(a). Photographs of the model snow cover distribution under the different conditions of tank experiments 1 - 4 are shown in Figures $8(\mathrm{~b})-(\mathrm{e})$. The field test was conducted for 24 hours. The snowfall time of the model snow to the snowstorm for 1 day is found from the Equation (1). Fifty grams of model snow were sprinkled uniformly over a period of $50 \mathrm{~s}$ from the upper stream side of the honeycomb plate using spraying equipment. In each tank experiment, a horseshoe-shaped whirlpool arises from a transverse plane on the windward side of the cube like in the field test. The snow cover was reduced by strong wind at the windward face and the two side faces. Moreover, it was possible to identify the situation of imitation snow sedimentation on the backward side. Furthermore, we can confirm the generation of the horseshoe-shaped whirlpool in a visualization experiment (Figure 8(f)). Figure $8(f)$ shows the generation of the whirlpool visualized employing the laser sheet method for the cubic model in the tank.

The deposition thickness of the model snow around the cubic model in tank experiments 1 - 4 was measured using the laser displacement gauge. The deposition thicknesses on the leeward and windward sides of the cube are shown in Figure 9.

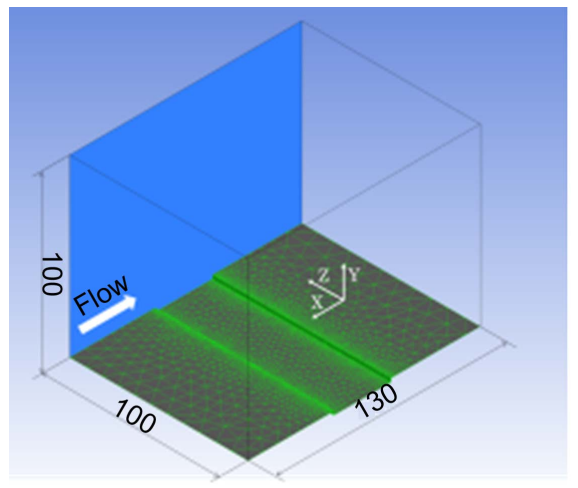

(a)

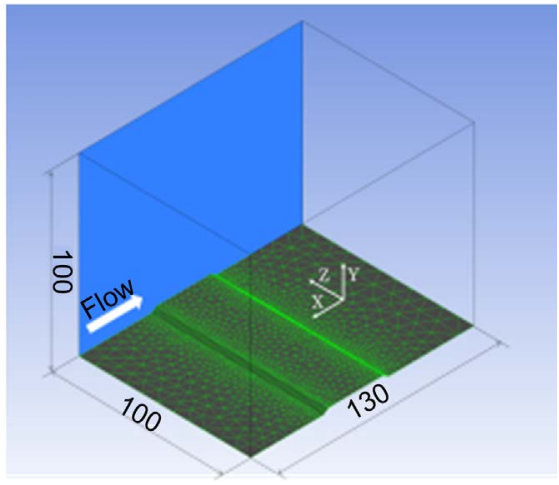

(b)

Figure 7. Regions of numerical analysis (unit: m). (a) Cut-earth model; (b) Embankment model. 


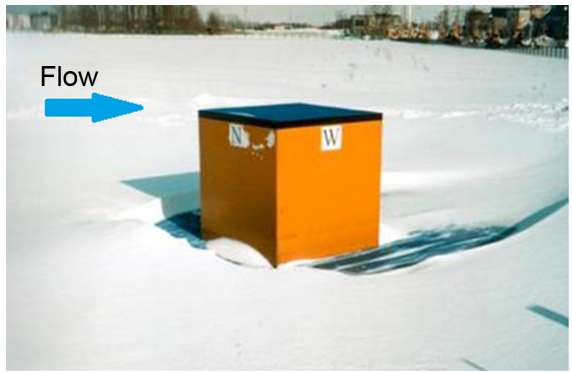

(a)

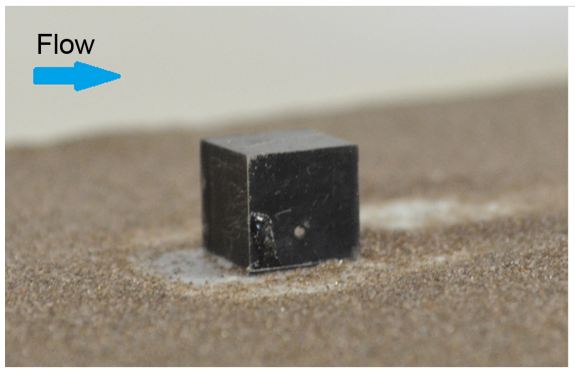

(c)

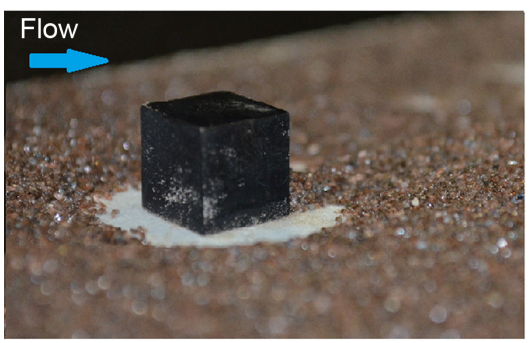

(e)

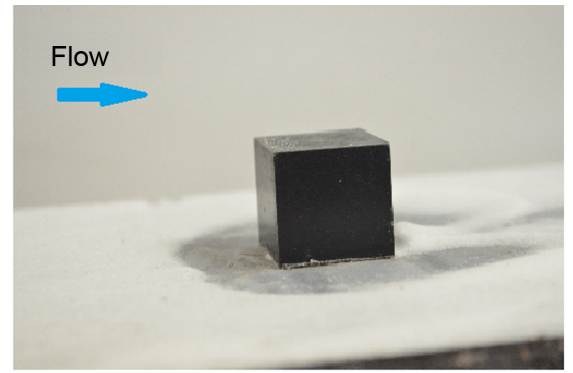

(b)

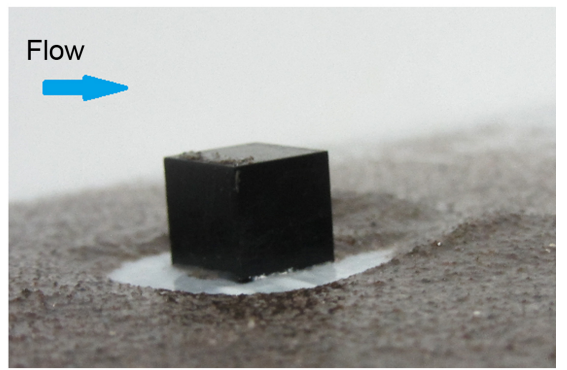

(d)
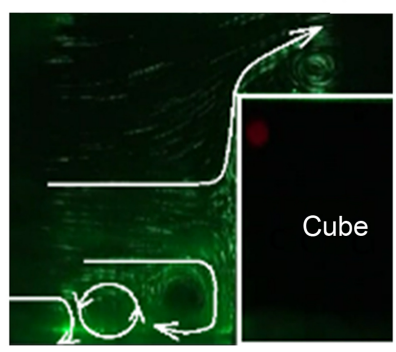

(f)

Figure 8. Snow covering results. (a) Actual phenomenon; (b) Experiment 1; (c) Experiment 2; (d) Experiment 3; (e) Experiment 4; (f) Laser sheet method.

The ordinate shows the ratio of the depth of accumulated snow or model snow $\mathrm{D}$ to the length of the cube $H$, and the abscissa shows the ratio of the distance from the cube center $X$ to $H$. The origin of the coordinate system is the center of the base of the cube. In the case of the real phenomenon, the mean wind speed was $5 \mathrm{~m} / \mathrm{s}$, the position $X / H=-0.5$ corresponds to the wall surface on the windward side of the cube, and there is strong scouring near the windward side of the cube $(X / H=-0.6--1.2)$. Moreover, there is snowdrift at $X / H=$ -1.5 , which is separated from the cube. In the snowstorm water tunnel experiments, as the Stokes number increases from experiment 1 to experiment 4 , the interval of complete scouring upstream of the cube decreases.

The Stokes number (St) is an index of the ability of particles to follow the flow field. When $\mathrm{St} \ll 1$, particles follow the motion of the fluid promptly. As St approaches 1 , particles struggle to follow the fluid motion and their motion becomes complicated. When St $\gg 1$, particles move independently of the motion of flow. Therefore, because particles float in accordance with the flow when St is small in experiment 1 , the scouring (erosion) range becomes large. In the case that St is large in experiment 4, particles do not likely follow the motion of flow 


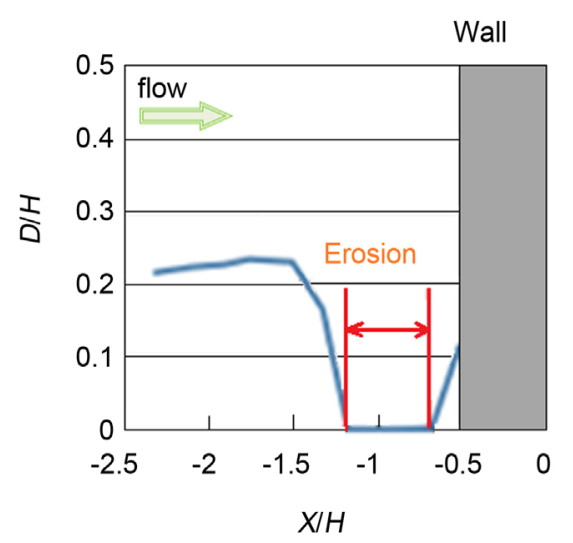

(a)

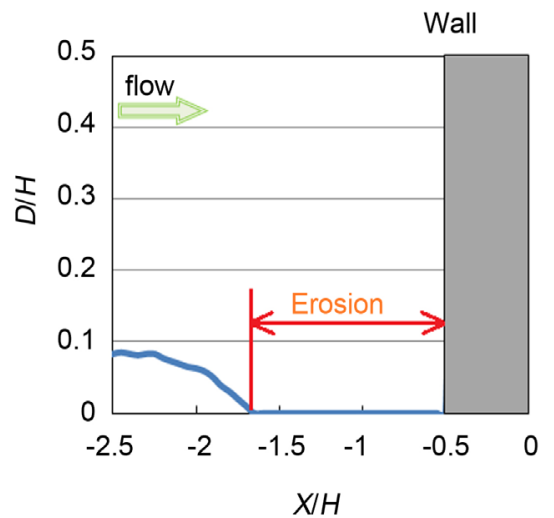

(c)
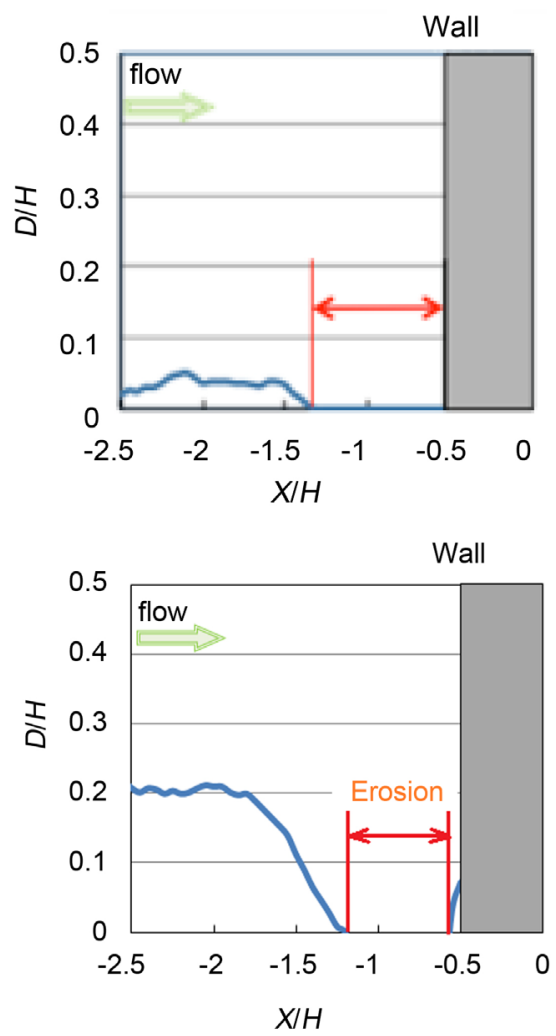

(g)

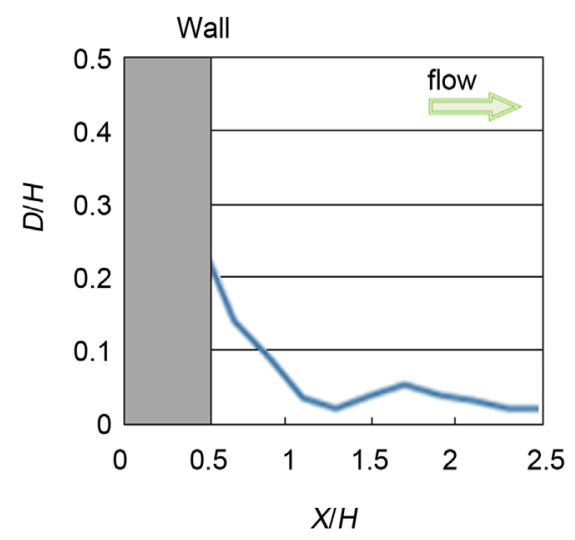

(b)

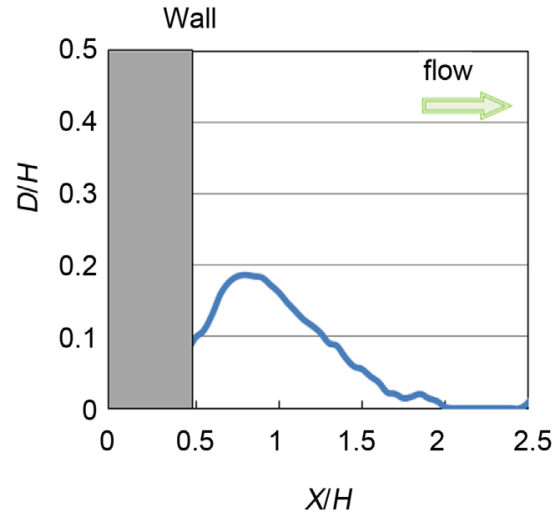

(d)
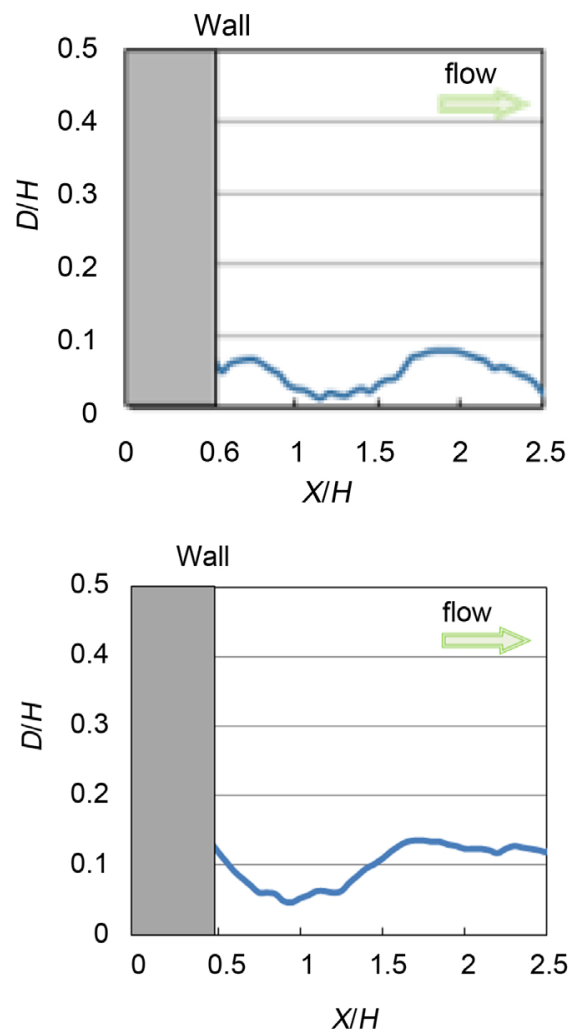

(h) 


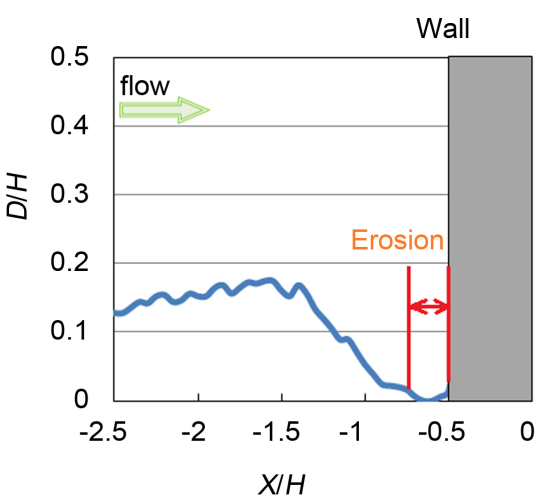

(i)

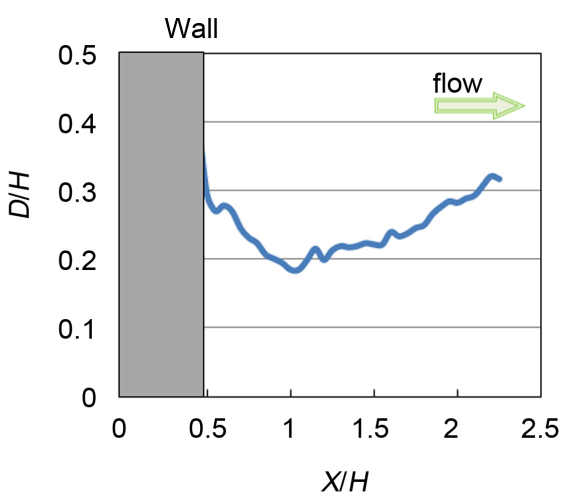

(j)

Figure 9. Snow depth distributions. (a) Actual phenomenon (windward side); (b) Actual phenomenon (leeward side); (c) Experiment 1 (windward side); (d) Experiment 1 (leeward side); (e) Experiment 2 (windward side); (f) Experiment 2 (leeward side); (g) Experiment 3 (windward side); (h) Experiment 3 (leeward side); (i) Experiment (windward side); (j) Experiment 4 (leeward side).

and are considered to accumulate on the windward side of the cube. When St = 0.574 in experiment 3 , which is almost equivalent to that for the real phenomenon, the windward snow-cover distribution of the real phenomenon is reproduced.

The leeward wall of the cube corresponds to $X / H=0.5$. In the real phenomenon, there is snowdrift around $D / H=1.7$ near the cube, and erosion closer to but separated from the cube at $X / H=1.0$ - 1.5. Among the water tunnel experiments, experiment 3, which had a St number similar to that in the field test, produced a leeward pattern that was similar to that of the real phenomenon.

\subsection{Snowdrift Distributions for Uneven Surfaces}

As stated previously, the laser displacement gauge could be used to make highly accurate measurements of a roughened surface (with roughness index \#1000) in comparison with a smooth surface. Furthermore, when the sedimentation velocity ratio and the Stokes number in a tank experiment were set almost the same as those for the real phenomenon, the actual snow cover distribution was largely obtained. Snowstorm tank experiments were thus conducted under these conditions for a cut-earth model and embankment model. The experimental conditions are given in Table 2.

The snowfall time of the model snow to the snowstorm for 10 days is found from the Equation (1). One-hundred grams of model snow were sprinkled uniformly over a period of $30 \mathrm{~s}$.

The experimental result obtained for the cut-earth model is shown in Figure 10. Figure $10(a)$ is a photograph of the experimental result, Figure 10(b) presents the thickness of the model snow deposition measured using the laser displacement gauge, and Figure 10(c) shows the numerical analysis result. The measurement of the deposition thickness of the imitation snow shows snowdrift in the lower cut part next to the upper and lower streams. Moreover, there was 
Table 2. Conditions of the snowstorm tank in the second series of experiments.

\begin{tabular}{cccc}
\hline & & Actual phenomenon & Water tank \\
\hline Particle diameter & $d(\mathrm{~mm})$ & 0.2 & 0.15 \\
Particle density & $\rho\left(\mathrm{kg} / \mathrm{m}^{3}\right)$ & 920 & 3980 \\
Sedimentation velocity & $W t(\mathrm{~m} / \mathrm{s})$ & 1 & 0.0348 \\
Velocity & $U(\mathrm{~m} / \mathrm{s})$ & 10 & 0.27 \\
Candidate length & $L(\mathrm{~m})$ & 2000 & 3 \\
Viscosity & $\mu\left(10^{-3} \mathrm{~Pa} \cdot \mathrm{s}\right)$ & 0.0167 & 0.724 \\
Stokes number & $S t$ & 0.61 & 0.62 \\
$\begin{array}{c}\text { Sedimentation velocity } \\
\text { ratio }\end{array}$ & $W t / U$ & 0.1 & 0.12 \\
\hline
\end{tabular}

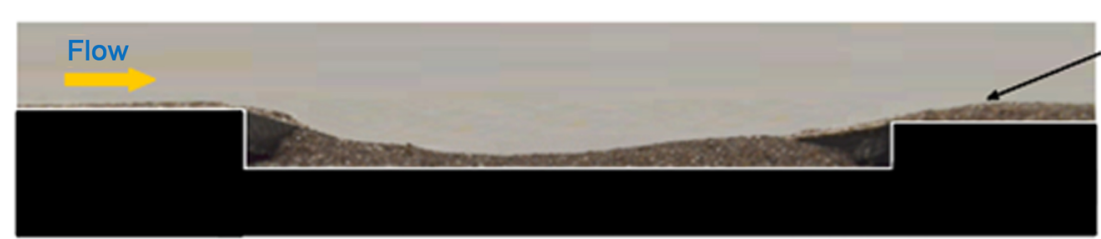

(a)

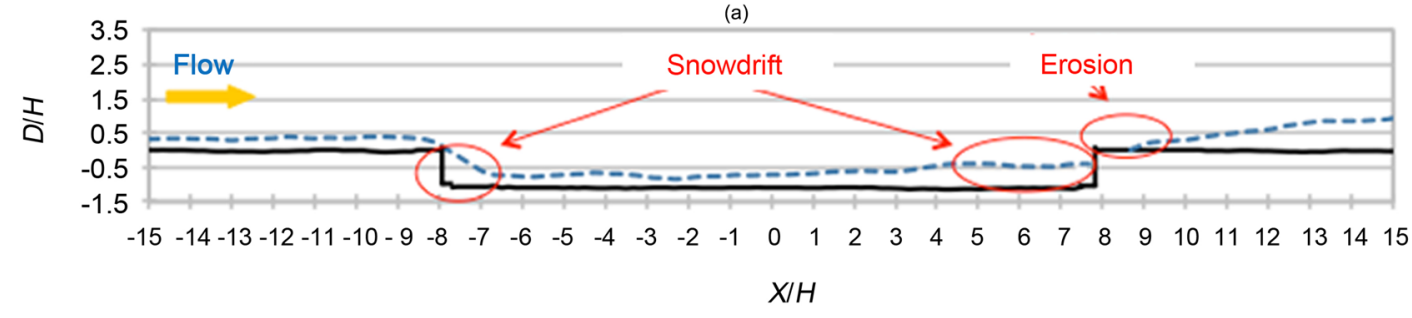

(b)

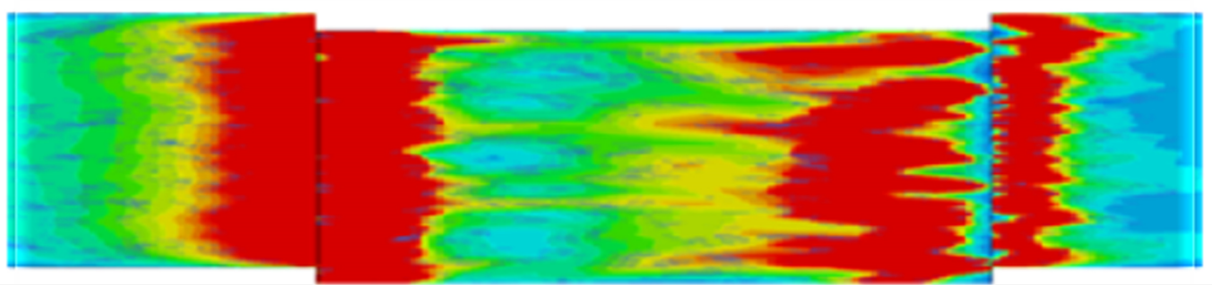

(c)

Figure 10. Model snow covering for the cut-earth model.

erosion in a hollow upper part next to the lower stream. The snow cover distribution of the numerical analysis is expressed as the volume fraction of particles in space. It is expected that the snow particle concentration and snow cover increase as the numerical analysis result transitions from blue to red. The results of the numerical analysis and snowstorm water tunnel experiment have similar tendencies.

Figure 11 shows the experimental result for the embankment model. The measurement of the imitation snow deposition thickness shows snowdrift at the foot of the slope next to the upper stream and that next to the lower stream. There was also increased deposition at the top of the slope next to the lower stream. As mentioned previously, the snow cover distribution of the numerical 


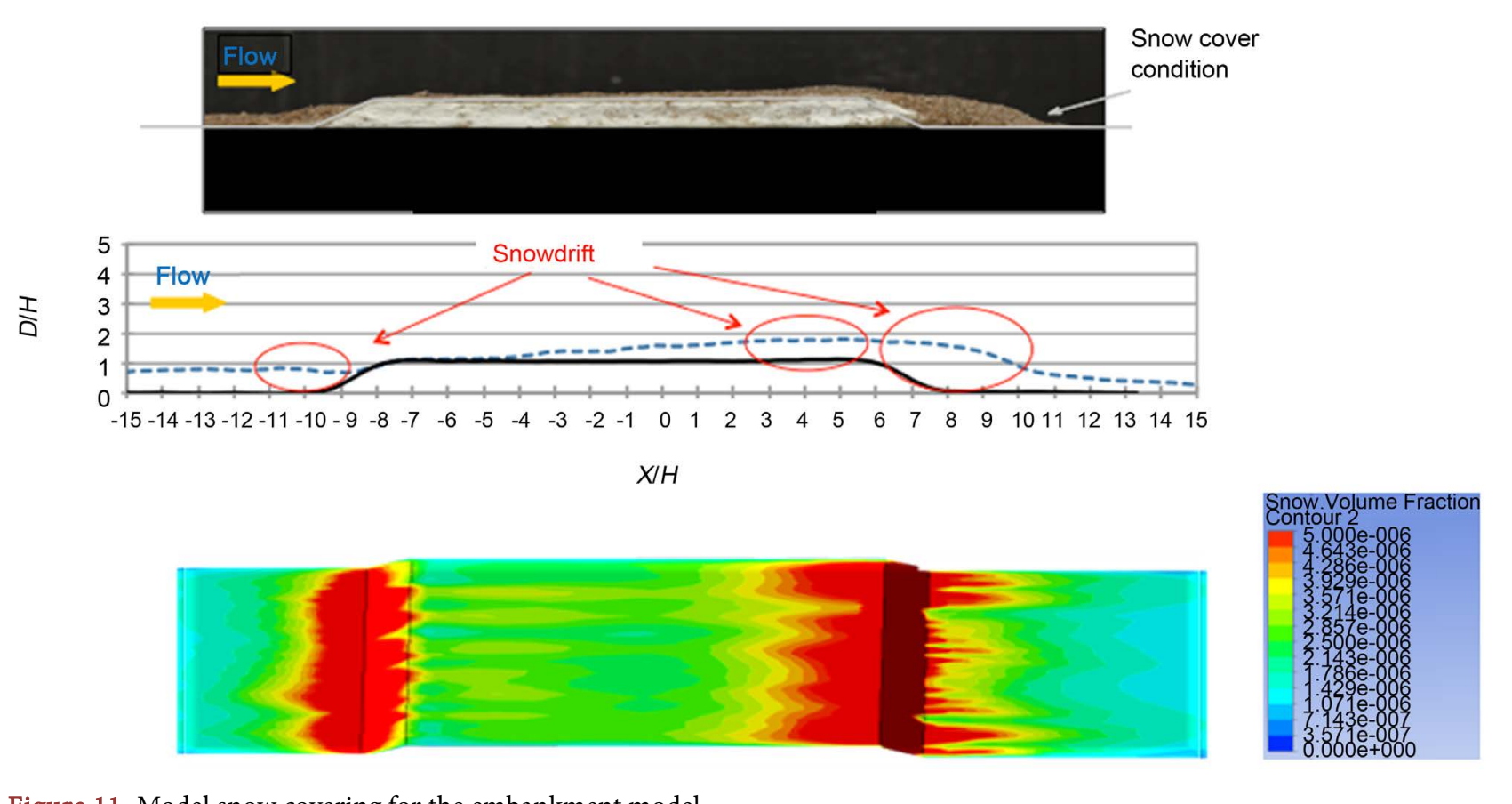

Figure 11. Model snow covering for the embankment model.

analysis is expressed by the volume fraction of the particles in space. It is expected that the snow particle concentration and snow cover increase as the numerical analysis result transitions from blue to red. The results of numerical analysis and the snowstorm water tunnel experiment have similar tendencies.

\section{Conclusions}

The present study examined the performance of a snowstorm water tunnel in reproducing the deposition of snow around a cube model and on an uneven road surface during a snowstorm. The following results were obtained.

- When the sedimentation velocity ratio and Stokes number in a tunnel experiment were set almost the same as those of a real phenomenon, the snow cover distribution around a cube model was well reproduced.

- In the case of a cut-earth model, there was snowdrift in the hollow lower part next to the upper stream and lower stream. Moreover, there was erosion in a hollow upper part next to the lower stream.

- In the case of an embankment model, there was snowdrift at the foot of the slope next to the upper stream and next to that of the lower stream. Moreover, the deposition of model snow increased at the top of the slope next to the lower stream.

\section{References}

[1] Anno, Y. (1984) Requirements for Modeling of Snowdrift. Cold Regions Science and Technology, 8, 241-252. https://doi.org/10.1016/0165-232X(84)90055-7

[2] Oikawa, S., Tomabechi, T. and Ishihara, T. (2007) Study of Wind Tunnel Similarity on Snowdrift around Buildings. Journal of Snow Engineering of Japan, 23-24, 133-152. (In Japanese) https://doi.org/10.4106/jsse.23.133 
[3] Iversen, J.D. (1979) Drifting Snow Similitude. Journal of the Hydraulics Division, 105, 737-753.

[4] Kind, R.J. (1976) A Critical Examination of the Requirements for Model Simulation of Wind-Induced Erosion/Deposition Phenomena Such as Snow Drifting. Atmospheric Environment, 10, 219-227. https://doi.org/10.1016/0004-6981(76)90094-9 